\title{
ESPIRAIS D'ASCESE: FORMAÇÃO PARA GESTÃO DE EQUIPES E GRUPOS NA ATENÇÃO BÁSICA EM SAÚDE
}

\author{
ESPIRAIS D'ASCESE:TRAINING FOR MANAGING TEAMS AND GROUPS IN PRIMARY \\ HEALTH CARE
}

\author{
Ana Maria Franklin de Oliveira ${ }^{1}$ \\ Jair Franklin de Oliveira Júnior ${ }^{2}$
}

Resumo $\mathrm{O}$ artigo apresenta uma experiência de formação de equipes da Atenção Básica e gestores da secretaria de saúde do município de Amparo, em São Paulo, na qual são feitas discussões de casos, num formato de grupo de supervisão, alterado pelo Método das Espirais D'Ascese. Este método busca apoiar os profissionais de saúde na ampliação da clínica e na gestão de grupos e coletivos, partindo dos referenciais teóricos do Método Paidéia e da psicologia de grupos para trabalhar inter-relações e conflitos. Selecionamos seis casos e através deles analisamos aspectos do processo de vinculação e amadurecimento deste grupo, que permitiram a transformação de sentimentos destrutivos em construtivos. A apresentação dos casos e sua discussão propiciaram manifestações do inconsciente grupal. É uma forma de o grupo falar de si mesmo através do caso clínico (ou de gestão), que funciona como metáfora dos sentimentos do grupo. Reconhecer e acolher as dificuldades fortalece o grupo, porque se percebe que todos têm fragilidades e que, ao compartilhá-las, há dissolução de angústias, medos ou outros sentimentos que obstaculizam a construção de soluções. Um grupo integrado, preparado e amadurecido prestará melhor assistência à saúde da população, com menos absenteísmo e adoecimentos e maior realização profissional.

Palavras-chave atenção básica; saúde da família; gestão; grupos; formação profissional.
Abstract This article presents a team training experience of Primary Care and managers of the secretary of health of the city of Amparo, Sao Paulo, where cases are discussed in supervised groups, altered by the method of Espirais D'Ascese [Spirals of Asceticism]. This method seeks to support health care professionals in the amplification of the clinic and in the management of groups and collectives, based on the theoretical references of the Paideia method and of the psychology of groups to work on interactions and conflicts. We selected six cases and analyzed aspects of the process of attachment and maturation of this group, which enabled the transformation of destructive feelings into constructive feelings. The presentation and discussion of the cases provided demonstrations of the group's unconscious. It is a way for the group to talk about itself through the clinical case (or managerial), which functions as a metaphor of the group's feelings. Recognizing and accommodating the difficulties strengthens the group because of the realization that everyone has weaknesses and as a result of their sharing, there is dissolution of anxieties, fears, and other feelings that hinder the construction of solutions. An integrated, prepared, and mature group will provide better health care to the population, with less illness and absenteeism and greater professional achievement. Keywords primary care; family health; management; groups; professional training. 


\section{Introdução}

Este artigo tem como foco o processo de formação de profissionais e gestores da Atenção Básica para gestão de grupos, equipes e serviços de saúde, por meio de um novo método pedagógico-terapêutico chamado Espirais D' Ascese. A formação se deu no contexto de um curso de especialização em gestão de sistemas e serviços de saúde, objeto de uma pesquisa-ação que avaliou a implementação do método e analisou os 18 projetos terapêuticos e de intervenção (seis deles apresentados neste artigo) desenvolvidos pelos profissionais-alunos. A finalidade é ilustrar o processo grupal e o trabalho com as resistências internas, evidenciando o amadurecimento das interrelações e as dificuldades ou facilidades na implementação de projetos criativos compartilhados ao longo do curso.

O termo 'ascese' (ou ascesis), que dá origem ao nome do método, vem da palavra grega askesis e significa 'exercício', 'esforço', 'explorar'. Definese o método como espirais de exercício, empenho, exploração e esforço para desenvolver potenciais de equipes e grupos. É uma versão revisitada do Método Paidéia (da Roda), que consiste em um conjunto de conceitos operacionais de apoio à cogestão e objetiva articular a produção de bens e serviços de saúde com a produção de instituições, organizações e dos próprios sujeitos envolvidos com o processo. Neste sentido, é um método de gestão, ainda que também possa ser considerado um método terapêutico e educativo (Campos, 2000).

As espirais lançam mão também das contribuições de Michael Balint e de autores que desenvolveram a base conceitual da psicologia de grupos, como Foulkes (1971), Bion (1975), Pichon-Riviére (1986), Cortesão (1989), Zimerman (2000), Osório (2000) e Oliveira Júnior (2000; 2003), dentre outros. ${ }^{3} \mathrm{Na}$ definição de Osório:

\footnotetext{
É a disciplina que disponibiliza e integra conhecimentos para sustentar a práxis com os sistemas humanos nesse limiar de uma nova era (...). O grupo (...) age como caixa de ressonância do reconhecimento da diversidade humana e instrumento propiciatório da convivência com os contrários ou dessemelhantes (Osório, p. 168, 2003).
}

O pensamento espiralado, que toma como referência o movimento paradigmático do universo em expansão, é o que mais se adapta à representação de um processo em permanente evolução, como é o das estruturas grupais (Osório, 2003). O método e os conceitos centrais utilizados não estão descritos neste artigo, por limites de espaço, mas encontram-se em outra publicação da autora e no Relatório Final da Pesquisa (Oliveira, 2008a e 2008b). Destacamos a utilização dos seguintes conceitos: setting, transfe- 
rência e contratransferência, ambiente protegido, insights, resistências, ego-auxiliar, continência afetiva, grupalidade, livre discussão circulante, ressonância afetiva, inconsciente grupal, papéis grupais, supostos básicos de grupo, padrão grupal, matrix grupal, linguagem não verbal, projeto terapêutico singular, clínica ampliada, cogestão, matriciamento, autocuidado, empoderamento, sociopatologias, tecnologias leves e relacionais, dentre outros.

\section{Análise do processo grupal na implementação do Método das Espirais D'Ascese em Amparo}

A escolha do Colegiado Gestor da Atenção Básica de Amparo, município de São Paulo, para a aplicação do método e avaliação de suas potencialidades e limites através de uma pesquisa-ação nos pareceu 'ideal', pois o grupo já se reunia regularmente e já praticava, em boa medida, o Método da Roda, promovendo rodas de planejamento, acompanhamento e avaliação. Já havia desejos, interesses, conflitos e uma história de luta pelo Sistema Único de Saúde (SUS) e pelo fortalecimento da Atenção Básica no município. Um percurso de muitas conquistas, muita construção, muitos impasses. Tudo isso fazia da equipe de Amparo um grupo especial, um espaço privilegiado para se trabalhar com a subjetividade grupal, em um período relativamente curto (um ano). Este era o tempo disponível, em função da inserção da pesquisa-ação no contexto do curso de especialização em gestão de serviços e sistemas de saúde que seria ofertado em 2007 pelo Departamento de Medicina Preventiva e Social da Faculdade de Ciências Médicas, da Universidade Estadual de Campinas (DMPS/FCM/Unicamp).

O curso foi realizado através de encontros quinzenais com um tutor horizontal, com formação em saúde da família e psicologia de grupos e ofertas teóricas no campo da gestão e da psicologia de grupos, além de outros temas demandados pelos alunos e apoio à distância, através da Internet (software Teleduc).

A seguir, apresentamos seis projetos analisados com a finalidade de ilustrar a aplicação do Método das Espirais D’Ascese através de ferramentas e conceitos dos métodos Paidéia (da Roda) e da psicologia grupal. Usaremos nomes fictícios para identificar as falas de modo a preservar o anonimato e o 'ambiente protegido' no qual o trabalho foi desenvolvido.

No primeiro encontro, foram trabalhados os objetivos do curso, a metodologia, o contrato e a definição do setting (local, horário, férias, programação). Discutiu-se o papel da coordenação/tutoria horizontal: a criação de vínculo e o cuidado com o setting, a presença de um profissional de apoio (gravação, registro do encadeamento das falas, observação da linguagem não verbal, como ausências, distribuição espacial dos participantes etc.), papel 
do apoio à distância (Teleduc) para disponibilização de materiais, correio, realização de fóruns, portfólios, dentre outros. Contratou-se a responsabilização de cada participante pela elaboração do Projeto Terapêutico ou de Intervenção na Gestão, que seria acompanhado pelo grupo até o final do curso e constituiria o Trabalho de Conclusão do Curso (TCC).

Os três encontros iniciais trataram de casos muito difíceis, complexos, situações que colocavam em teste os 'limites' das equipes. Apareceram sentimentos esquizo-paranoides: medo de exposição, de perseguição, de quebra de sigilo, desigualdade de poder fora do grupo, particularmente devido à presença da gestora municipal, além de um forte sentimento comum de impotência, insegurança, medo e angústia paralisante.

Uma análise da disposição espacial dos participantes no início do grupo evidenciou uma franca desigualdade de poder. De um lado da roda, sentavam os apoiadores e os coordenadores mais antigos; do outro, os residentes e os coordenadores mais novos. Como se dividindo a roda ao meio, sentava-se uma pessoa importante na gestão da Secretaria de Saúde e, no outro lado, a coordenadora do grupo, a apoiadora e o professor convidado. Também se observou que nos primeiros encontros esta pessoa importante na gestão assumia claramente a liderança do grupo, procurando sempre sintetizar ou fazer a conclusão das falas. Em uma avaliação intermediária do processo, realizada em agosto de 2007, os integrantes do grupo puderam expressar a ansiedade e insegurança de exposição inicial:

(...) no início, para mim, era uma coisa nova, uma experiência nova, que gera ansiedade, eu não sabia para que lado podia ser! Podia ser tudo usado como a gente está usando, dialogando, mas de repente, poderia criar um mal-estar grande. Mas a gente passou por cima disso e conseguiu vencer e criar compromissos de entender esses papéis. Eu acho que isso foi muito rico (Joana).

(...) apesar de eu falar pouco e participar, acho que estou aproveitando muito. Não é porque eu não me coloco, talvez até devesse me colocar mais. Mas não é porque eu não falo, não só eu, mas outras pessoas. A gente não está só de corpo presente, a gente está aproveitando (Lúcia).

(...) Contribuiu para esse sentimento de insegurança e ansiedade a presença de pessoas da gestão municipal no grupo: "Você ter um gestor que está conhecendo aqui no grupo, mas também ter certo 'policiamento' de gestor em cima de você. A sensação, o quanto de liberdade você teria num curso de gestão junto com seus gestores. Isso me deixava um pouco ansioso..." (Eduardo).

O sentimento esquizo-paranoide (de medo de exposição, de perseguição) é comum no início dos processos grupais e foi superado com a cons- 
trução gradativa de um 'espaço protegido', que permitiu uma abertura necessária à discussão dos casos e 'continência' para acolher sentimentos difíceis e dificuldades objetivas enfrentadas no cotidiano dos serviços. Também foi fundamental para esta construção a capacidade das pessoas mais ligadas à gestão da secretaria em lidar com as diferenças de papéis e com as críticas.

(...) eu me sinto completamente à vontade aqui, para ouvir e para falar, para fazer os comentários. Eu acho que isso a gente construiu aqui, esse clima de proteção para a gente se sentir a vontade até para fazer comentários (...), são aquelas coisas que 'pegam', que nos indignam muito (Joana).

(...) eu acho que a minha presença aqui, de uma forma ou de outra, também traz um crescimento para vocês e para mim também, eu falei bem isso. Sabendo que todo mundo vai falar o que pensa; inclusive eu (Leninha).

(...) Tudo o que está sendo falado aqui é uma escola para mim. Tudo é novidade, tudo é novo. Eu sei que com o que eu posso contribuir eu tenho contribuído, mas para mim está sendo fantástico (Lúcia).

As devolutivas e as observações realizadas ao longo dos primeiros encontros alteraram, aos poucos, tanto a disposição geográfica dos participantes como a disponibilidade para expor-se, conformando-se a roda, de modo diferente a cada encontro, com as pessoas se 'empoderando' e assumindo a própria voz.

Um aspecto técnico importante na coordenação e no manejo de grupos, que merece ser destacado, é o processo de 'livre discussão circulante' e a associação livre de ideias no grupo. O coordenador estimula, facilita as manifestações verbais ou não verbais de modo a ter acesso à comunicação consciente e, em seguida, ao inconsciente grupal e conhecer o grupo em sua psicologia profunda. Os casos clínicos trazidos ao acaso para discussão são manifestações do inconsciente grupal que se revelam na escolha do caso por um membro do grupo e a 'livre discussão circulante' que se segue. É uma forma de o grupo falar de si mesmo pela metáfora do caso clínico. É uma psicoterapia grupal sem ser tratamento psicológico individual.

Para o coordenador capacitado, a discussão dos casos permitirá o acesso a sentimentos do grupo, possibilitando ajuda, em um nível emocional profundo, ao grupo como um todo. Com o tempo, o grupo, em seu processo de amadurecimento, deverá sair da condição de 'filho' que espera ser 'nutrido' pelo coordenador. O grupo que vai amadurecendo cria um vínculo mais fraternal, de pessoas dentro do mesmo nível. Porque o filho é aquele imaturo que espera que o pai e a mãe tragam sempre as soluções. E projeta este papel no coordenador, no gestor, no professor, ficando sempre à espera 
de soluções prontas, de fora para dentro, sem se corresponsabilizar por construí-las com seus pares (Oliveira Junior, 2003).

Também é importante observar no grupo a linguagem não verbal expressa, por exemplo, pela ausência, que pode significar resistência ao trabalho. É recomendável buscar contato com o profissional que se ausentou a mais de um encontro, para saber por que não está vindo e mostrar que o grupo se importa, que a pessoa faz falta no grupo. Observar também quem fala pouco. Isto não quer dizer que não está aproveitando, mas é bom estimular para que se encoraje e se exponha mais. Outros falam demais e é importante observar que todos têm o mesmo direito de falar num grupo e, se uns falam demais, é porque outros falam de menos. Um grupo maduro estimula a participação de todos, devido ao respeito com o que é falado e à prática do acolhimento, sem julgamentos, que deve ser garantido pelo coordenador.

O grupo, por definição, pressupõe a criação de vínculos afetivos, ou seja, um fluxo entrecruzado de afetos. Isto significa que as pessoas se afetam mutuamente. Mas não para julgar e definir o que é certo ou errado, e sim para trocar vivências, experiências, para que cada um consiga sair do lugar que está e crescer um pouco mais, com o apoio dos outros. Dificuldades todos têm, seja nos padrões de personalidade, nos níveis de experiência profissional, nos inter-relacionamentos. $\mathrm{O}$ amadurecimento opera à medida que se aprende a lidar melhor com as diferenças e dificuldades, partindo do pressuposto de que todos são imperfeitos e que a vida é imperfeita. Quanto mais convivemos com este dado de realidade, melhor a vida se torna, pois buscar a perfeição é algo muito sofrido e meta inatingível.

O primeiro caso apresentado foi bastante complexo e focalizou uma família de traficantes, onde havia uma pessoa em tratamento de tuberculose supervisionado, resistente ao mesmo. Havia medo da equipe em relação à condição de traficantes, além de uma série de outros problemas de ordem social e familiar, que podem ser vistos na descrição do caso no Relatório da Pesquisa (Oliveira, 2008b). Como não havia agentes comunitários de saúde (ACS) da microárea e ninguém se dispusesse a ir, a coordenação se viu obrigada a designar um novo ACS responsável, revelando também certo medo da equipe de enfrentar junto o problema desta família onde existe uma pessoa em que predomina o instinto de morte. A questão é: como salvar esta pessoa da morte?

O medo que este caso evocou no grupo pode ser pensado num nível mais profundo do inconsciente grupal como o medo dos aspectos destrutivos do próprio grupo. A razão pela qual este caso foi escolhido, dentre tantos outros possíveis, parece ser a necessidade do grupo de expressar suas dificuldades de enfrentar a morte e o sentimento de impotência diante dos aspectos destrutivos da psique. Parece haver um aspecto muito contaminado no próprio grupo, que não sabe como vencer a morte (aspectos destru- 
tivos) para predominar a vida (aspectos construtivos) do grupo. A tendência deste grupo é ir evidenciando estes aspectos através de brigas e desentendimentos, que precisam ser acolhidos, como no caso da família em questão, para haver um choque de vida. O grupo se sente como uma família de traficantes. Como podem ser ajudados e predominar a saúde e a vida? É como se a mensagem oculta neste caso fosse que a coordenação do grupo também é impotente para evitar os aspectos destrutivos que podem levar o grupo à morte. Este caso revela a suposição de que a coordenação também é impotente para injetar vida no grupo. A postura da coordenação do grupo deve ser de apoio para: ajudar a família/grupo a sobreviver; buscar um contato com a mãe/gestora no sentido de buscar uma parceria para a construção do projeto terapêutico para a família/grupo e desmistificar o papel de polícia/ controle da coordenação frente aos membros da família/grupo.

Do ponto de vista da gestão, podem ser abordados aspectos como a ausência de ACS com vínculo na microárea. Esta ausência revela as dificuldades da gestão na substituição de profissionais das equipes. Também pode ser vista como uma falta de corresponsabilidade do restante da equipe pela criação e manutenção dos vínculos com os usuários, como se eles estivessem sob a responsabilidade do ACS ausente. A postura da coordenação da Equipe Saúde da Família (ESF) pode também ter sido vista pela equipe como 'autoritária' ao designar um ACS para a função, ao invés de compartilhar o problema e corresponsabilizar a equipe na busca de uma solução compartilhada.

Em relação ao Projeto Terapêutico Singular (PTS), muito se avançou no trabalho contra o estigma e a exclusão da família pela comunidade, particularmente na creche e na escola, onde o caso foi discutido. A tuberculose foi controlada, embora o paciente tenha se recusado a tratar a adicção.

O segundo caso selecionado foi de uma paciente com diabetes tipo II e insuficiência renal crônica, resistente ao tratamento na Unidade Saúde da Família (USF), que se mostrava agressiva, com reiteradas negativas em receber as visitas domiciliares, o que obstaculizava o trabalho da equipe de coordenar o cuidado e garantir a continuidade do tratamento. Isto causava um sentimento de tensão, impotência e irritação nos profissionais responsáveis.

A discussão do caso no grupo propiciou um contato com sentimentos transferenciais e contratransferenciais inconscientes: irritação, raiva, agressividade e impotência vividas pela paciente em relação a sua enfermidade e projetadas na equipe, que reagia em consonância com os mesmos. Para agravar as dificuldades do caso, a paciente completamente dependente e contando com uma rede social fraca viu seu pedido de ajuda (para a aplicação de insulina no domicílio) recusado pela equipe, por razões normativas da USF. Este caso exigia flexibilidade, mesmo que temporária, pois a paciente apresenta dificuldades socioeconômicas, uma rede social mínima e a visão totalmente comprometida, o que a impede de deslocar-se até a USF, 
conformando um caso de risco grave de vida. A flexibilização era necessária também para promover a consolidação do vínculo que a situação de vulnerabilidade física e social da paciente exigia. O contato com estes sentimentos permitiu que a profissional responsável pelo PTS decidisse se afastar temporariamente do caso, de modo a 'descontaminar' a relação e permitir que outro profissional da equipe ainda não 'contaminado' o assumisse. Isto foi importante para investir novamente na vinculação, aprofundar o diagnóstico da perspectiva da saúde mental, resgatar a confiança da paciente e acolher suas queixas e seus sentimentos em relação à doença e à equipe para a retomada do tratamento. O projeto teve sucesso, permitindo mais tarde a retomada do caso pela profissional responsável, que a acompanhou até a mudança da paciente para outro bairro, fora da área de abrangência da equipe.

Neste caso, é interessante olhar para a irritação e a raiva como expressões distorcidas do sentimento amoroso, pois o sentimento contrário ao amor é, na verdade, a indiferença. O não importar-se, não responsabilizarse, omitir-se, seria, neste caso, um problema mais grave. A indiferença e o individualismo exacerbado são hoje sociopatologias comuns, como uma 'lepra social' que faz com que deixemos de nos importar, de sentir compaixão e solidariedade, abandonando as questões do sofrimento psíquico e social à esfera de um individualismo atroz. Neste sentido, também é importante ressaltar que a raiva e a violência são expressões distorcidas de uma agressividade saudável, pois a agressividade é necessária para que ocupemos nosso lugar no mundo, defendamos nossos pontos de vista, nossa singularidade e nossos interesses.

Entrar em contato com o sentimento contratransferencial de raiva e com a postura obstinada de tratar de forma similar e normativa todos os casos de pessoas insulino-dependentes, sem perceber a singularidade e a necessidade de flexibilização que o caso exigia, permitiu uma atitude (afastamento temporário) que propiciou o restabelecimento do vínculo com a equipe e a garantia de continuidade do tratamento.

O terceiro caso selecionado trazido por um coordenador, médico de uma equipe que atua em área rural, envolvia violência intrafamiliar e uma história de vida marcada por carências e abusos de toda ordem. Trata-se de uma mulher de 25 anos, que comparecia frequentemente à unidade com queixas genitais sem causa orgânica aparente. Desde sua infância sofreu violência física, psicológica e sexual, vivendo em situação de exclusão social, com grande dificuldade de manter vínculos afetivos. Teve diversos relacionamentos com homens que reproduziram o ciclo de violência, possuindo uma filha de 10 anos que também vem sofrendo agressões por parte do padrasto e da própria mãe. O PTS discutido pelo grupo envolveu a solicitação de auxílio da assistência social, o desenvolvimento de parcerias locais para garantir maior inclusão social, o apoio para a obtenção de trabalho, 
a capacitação da ESF para atuar como ego-auxiliar e a reflexão sobre as reproduções da violência no âmbito da própria equipe e as alternativas para lidar com casos como este, comuns na comunidade rural assistida. A partir das primeiras intervenções previstas no PTS, a usuária foi mostrando-se aberta ao apoio da equipe. Conseguiu um emprego temporário e passou a produzir artesanato como forma de complementar sua renda. O psicólogo da USF passou a realizar visitas domiciliares, nas quais trabalhava com mãe e filha o autocuidado e as dificuldades cotidianas de ambas. Como a usuária costumava faltar aos atendimentos agendados, a equipe colocou-se aberta para acolhê-la nos momentos em que ela própria os procurasse, o que possibilitou maior aproximação e o estreitamento do vínculo. A equipe vem apoiando a usuária no sentido de estimular uma reestruturação familiar menos violenta. Este PTS possibilitou, ainda, um efeito não esperado na dinâmica da própria equipe. A partir das discussões sobre a violência e os conflitos gerados pela desigualdade sociocultural local, a equipe pôde analisar sua forma de atuação frente a diversos problemas sociais presentes no território e houve uma diminuição dos conflitos internos à equipe. Isso promoveu novas práticas de saúde voltadas para esta população que tem na violência um fator intrínseco do coletivo local. A equipe passou a fazer avaliação de risco e vulnerabilidade, dando atenção para a violência como geradora de agravos físicos e mentais e a ampliar suas intervenções para a abordagem das dimensões subjetiva e social no processo saúde-doença.

A análise do conteúdo inconsciente grupal destes três primeiros casos evidenciou dúvidas acerca da potência do curso para mudar o sentimento de impotência do próprio grupo. O insight propiciado pelo contato com sentimentos de impotência, de angústia paralisante e de raiva, aliado às contribuições do grupo, seja na análise e interpretação dos problemas levantados, seja na criatividade que pautou a construção dos PTSs, trouxe empoderamento aos profissionais, de modo a buscarem implementar novas práticas a partir dos 'novos olhares' que ampliaram a clínica e redefiniram as formas de gestão do cuidado e do serviço a partir dos casos discutidos.

Evidenciava-se nesta altura dos encontros a efetiva existência de um 'espaço protegido' em que as rodas começaram a se transformar em espirais e o grupo passou a discutir o processo de trabalho com identificação de dificuldades e sentimentos, obtendo maior discernimento sobre os limites com os quais é necessário lidar, como evidenciam os depoimentos da avaliação intermediária (agosto de 2007):

(...) a grande vantagem desse espaço é que a gente está discutindo só processo de trabalho. Ou o processo de trabalho de gestão ou o processo de trabalho da produção do cuidado ou o processo de trabalho em equipe (Alaíde). 
(...) esse espaço, eu acho que propicia isso em um grupo maior, da gente perceber que os nossos problemas são muito parecidos, que a gente tem dificuldades, que tem situação que, talvez, a gente não enxergue que é a cegueira institucional. Então, está ajudando bastante [sic] (Célia).

(...) a gente começa a enxergar as coisas, inclusive coisas que não estão ao nosso alcance e a gente até precisa baixar um pouco a nossa expectativa... Porque eu acho que a gente não pode ter uma expectativa em querer mudar coisas que estão postas, que são mais complicadas (Joana).

Ao centrar-se na tarefa, orquestrada pelo desenrolar das discussões dos casos e pelo lidar construtivo com os conflitos e as dificuldades, pôde-se vivenciar uma grupalidade e aprender a lidar melhor com as inter-relações. Ao mesmo tempo, além da contribuição do grupo para o caso discutido, as reflexões desencadeadas contribuíram para que cada membro repensasse suas práticas e experimentasse uma forma diferente de lidar com os conflitos e também com as potências e os limites de cada um e com as próprias inter-relações que se dão no coletivo. Os resultados positivos começavam a aparecer, como evidenciam as seguintes falas:

Acho que o principal problema nas unidades é o relacionamento humano. Eu acho que se a gente não trabalha a equipe como seres humanos que estão ali lado a lado, que têm as suas qualidades e as suas dificuldades, a gente não consegue fazer um processo de trabalho adequado (Alaíde).

A própria mudança no formato do que está se propondo para o colegiado de PSF já mostra um pouquinho dessa sementinha que está dentro da gente (Ivana).

No percurso das discussões dos casos que se sucederam, apareceu uma forte expressão de frustração e descontentamento por parte de uma participante que pode ter atuado como 'porta-voz inconsciente' do grupo. Tais sentimentos de frustração foram expressos com agressividade. A coordenação teve dificuldade de lidar com sentimentos contratransferenciais também agressivos, tomando uma atitude normativa, ao evitar a abertura do espaço para uma avaliação do curso mais geral naquele momento, de modo a ouvir os demais integrantes do grupo. Uma avaliação estava prevista para uma das sessões seguintes. No entanto, esta integrante do grupo pode ter funcionado inconscientemente como 'porta-voz' da frustração do grupo em relação ao fato de não tratar-se de um curso tradicional de gestão, mas de uma proposta que se propõe a trabalhar com a subjetividade, com sentimentos que dificultam ou impedem a realização das tarefas. 
O grupo, entretanto, elaborou melhor este 'mal-estar' durante a avaliação, na qual o curso foi muito bem avaliado. No entanto, era necessário acolher os sentimentos de frustração expressos pela participante como um sentimento real. É provável que expressasse também resistências internas a fazer o trabalho intrapsíquico. Esta hipótese se baseia no fato de ter explicitado no contrato inicial do curso seus objetivos e sua metodologia, que correspondiam ao que estava sendo ofertado, e também pelo fato de estar realmente mexendo em aspectos das personalidades e em possíveis 'feridas narcísicas'.

Um suposto básico da dinâmica grupal trabalhado por Bion (1975) é o de luta e fuga. Trata das manobras para dividir a coordenação, unindo os alunos numa luta, que ajuda a não enfrentar os verdadeiros problemas. Cabe ao coordenador a difícil arte de revelar, na medida e no tempo certo, a manobra para desmistificar a luta e lidar com os sentimentos verdadeiros. No grupo, estes sentimentos apareceram em determinados momentos como frustração e agressividade, que poderiam estar relacionadas, no caso, a uma dificuldade não revelada deste participante de 'inclusão digital' para utilização das ferramentas de educação a distância, mas não só.

Observaram-se também algumas tentativas de manipulação inconsciente, que buscaram cindir a equipe de coordenação, endeusando uns e 'satanizando' outros, através de elogios e apologias da transmissão de conhecimento em detrimento da análise do processo grupal, o que também pode ser compreendido como resistência ao trabalho intra e interpsíquico. Um aprendizado importante deste momento foi não adiar o enfrentamento de situações difíceis e acolher os sentimentos quando apareceram. A revelação e o contato com os sentimentos defensivos ajudam a manejá-los melhor, e os integrantes percebem que tais sentimentos 'negativos e obstrutivos' podem ser revelados e acolhidos pelo grupo, de modo a não obstaculizar, mas fortalecer o processo de amadurecimento e o aprendizado de manejo da grupalidade.

À medida que fomos trabalhando as defesas e os limites do próprio grupo e da Estratégia de Saúde da Família na resolução de determinados problemas, o grupo cada vez mais saiu da condição de dependência, luta e fuga, vitimização e culpabilização externa para a de diagnóstico, interpretação e construção de soluções criativas.

Pode-se observar ainda o surgimento de outro suposto básico estudado por Bion (1975), o do 'acasalamento', quando o grupo se une ao padrão (coordenador) para produzir novas elaborações e percepções, 'novos filhos'. Observa-se então a matriz (que vem de mater/mãe), fenômeno estudado por Oliveira Júnior (2000), que evidencia o espaço grupal com a potencialidade de um útero materno, capaz de gerar novas ideias.

Os PTSs que se seguiram evidenciaram este efetivo amadurecimento do grupo para coprodução de sujeitos coletivos potentes a fim de gerar soluções para situações complexas, como patologias mentais graves em 
indivíduos com rede social frágil, democratização de espaços coletivos, novas ferramentas na abordagem familiar, projetos intersetoriais, dentre outros, que exigem adequado manejo de tecnologias relacionais, como as apresentados neste artigo.

Neste contexto, surgiu também em nível do inconsciente grupal outro suposto básico estudado por Bion (1975), o da dependência, evidenciado na busca de respostas nas lideranças e de aprofundamento teórico. Este suposto é muito presente na relação dos serviços com as instituições de Ensino Superior.

Num contexto de grupanálise, poderíamos adentrar em conteúdos emocionais inconscientes dos profissionais frente às dificuldades relativas aos casos trazidos por eles para discussão. Este não era, entretanto, o objetivo deste trabalho que visa a proporcionar espaço adequado e continente para a verbalização e superação destes conflitos num plano operativo, conforme a técnica desenvolvida por Pichon-Riviére (1986). Não se trata de tratamento psicoterápico, apesar de, às vezes, a distância entre um e outro ser reduzida. O coordenador deve, entretanto, tomar o cuidado de não misturar as coisas.

Os aprofundamentos teóricos são necessários, mas não podem ser impeditivos do caminhar do grupo, à medida que o conhecimento que o grupo já detém, em função de sua prática cotidiana na USF, é suficiente para a realização de inúmeras tarefas, que acabam não sendo realizadas devido aos conflitos intra e interpsíquicos em nível de trabalho de equipe. Tais defesas atuam como forma de postergar ou evitar a passagem da pré-tarefa à tarefa, impedindo a realização da potência do grupo. Funcionam reafirmando uma expectativa imatura de que as soluções dos problemas exigem sempre um aporte externo, que serão dadas por mais conhecimento teórico ou por especialistas detentores de todo o saber.

Após o trabalho com este tipo de defesa, foram discutidos projetos de intervenção bastante criativos que, no entanto, não puderam ser analisados aqui face aos limites físicos deste artigo, como, por exemplo: a revisão do papel dos ACSs; uma pesquisa e revisão da estratégia de prevenção de câncer de colo uterino; a formação de grupos de alcoolistas e familiares na USF; uma proposta de maior integração da ESF com a atenção especializada; a revisão do matriciamento e a necessidade de maior apoio matricial em uma USF nova, além de uma estratégia de ampliação e fortalecimento dos conselhos locais de saúde.

Foi trabalhada a importância da criação de um ambiente protegido para que os sentimentos ditos 'negativos', como medo, fragilidade, inveja, competição, raiva e agressividade pudessem aparecer sem retaliações ou uso destrutivo na ambiência profissional. O contato e a exposição destes sentimentos no ambiente grupal permitem a limpeza do 'lixo psíquico' (Osório, 2000), o que por si só já é terapêutico e permite o contato com a fragilidade 
alheia, trazendo a consciência de que todos possuem pontos fracos, o que se traduz em força e potência, ainda pouco conhecidas e passíveis de realização.

Um caso ilustrativo foi apresentado por uma coordenadora de uma USF nova que evidenciou sua dificuldade em implementar algumas diretrizes do PSF, acompanhada de um pedido de maior apoio matricial. Inicialmente, esta solicitação foi criticada pelos gestores presentes, que talvez tenham feito uma leitura acusatória de 'insuficientes recursos de apoio'. A resposta defensiva apontou a larga experiência desta coordenadora e a não necessidade do apoio. O grupo discutiu, então, a importância de se respeitar o pedido e a exposição da fragilidade, destacando a coragem desta coordenação de expor suas dificuldades e inseguranças no grupo. O grupo ajudou na construção de um projeto de apoio mais intensivo, que apresentou resultados importantes ao longo de sua implementação.

O quarto caso selecionado evidenciou uma profunda mudança de perspectiva do grupo no sentido de sair da condição de impotência e vitimização: tratou da abordagem familiar de um paciente psicótico, com relacionamentos familiares e rede social quase inexistente e sem adesão a tratamento do Centro de Atenção Psicossocial (Caps). O usuário, alcoolista de 55 anos, recebe sua aposentadoria no banco e administra seu dinheiro, evidenciando capacidade de prover-se e autonomia para locomoção, embora apresente sérios problemas com a higiene pessoal e da casa. Não costumava tomar banho, limpar a casa ou lavar roupas. Não permitia que as pessoas da família entrassem em sua residência, 'defendendo-a' como um território demarcado pela defecação. A geladeira permanecia desligada, com alimentos podres que colocavam em risco sua saúde. Houve episódios de intervenção forçada, como realização de faxinas pela equipe, solicitação de intervenção da Vigilância Sanitária e encaminhamento ao Caps, sem adesão ao tratamento. O PTS evidenciou a necessidade de atuar em conjunto com o Caps, de modo a sustentar o tratamento no tempo e discutir os papéis de cada serviço. A equipe investiu no aprofundamento do vínculo com a ACS, que realizou um trabalho paciente e sensível e conseguiu aprofundar o conhecimento sobre a família do usuário e sua rede social, ao mesmo tempo que foi estreitando os laços com ele. A medicação, que não era revista há alguns anos, foi mudada e o usuário passou a alucinar menos. Foi descoberta uma irmã, com a qual ele ainda possuía vínculo, que se responsabilizou pela higiene da casa, com a permissão do paciente, que concordou com a manutenção da geladeira ligada. A equipe passou a compreender as atitudes do paciente em função de sua história familiar e de seu sofrimento mental. A discussão sobre as redes sociais sensibilizou a equipe para montar um grupo de convivência com pessoas que possuem transtornos mentais e que se tratam na USF, como esse usuário, que passou a participar do grupo. A ideia do 'grupo de convivência' é voltada para a produção de saúde e, neste caso, 
consubstancia um grupo de artesanato que se reúne periodicamente e é autogerido. Esta ação se estendeu para vários outros serviços, muitas vezes substituindo os grupos por enfermidades (hipertensos, diabéticos). A USF e o Caps se aproximaram e este iniciou um 'matriciamento' para os profissionais que coordenam o grupo.

O quinto caso selecionado foi de gestão da relação de uma USF com uma entidade filantrópica evangélica, que tem por finalidade a recuperação de jovens e adultos dependentes de drogas, fumo e álcool. A principal dificuldade trazida foi a de a instituição não atender às normas da Agência Nacional de Vigilância Sanitária (Anvisa) que regulamentam o funcionamento destes serviços: a precária estrutura física e de recursos humanos e o questionamento do papel da USF junto a estes usuários temporários. O Projeto de Intervenção propôs a realização de uma 'roda' para problematizar a situação da entidade com os atores envolvidos; evitar uma postura autoritária (de autoridade sanitária ou de educador em saúde) e desenvolver uma postura de agente facilitador; construir um projeto interinstitucional para melhorar a infra-estrutura; abordar o serviço de forma não tradicional; organizar o atendimento aos usuários, mesmo sem entrar na questão da dependência química; e estruturar a equipe do PSF para responder a essa demanda de forma a se corresponsabilizar, criar parcerias e ampliar o olhar. No processo de coconstrução do projeto intersetorial, foi proposto melhorar a estrutura física, com arrecadação de fundos para a reforma, cuja primeira etapa já foi concluída em 2007. Foi negociada a forma de atendimento médico e odontológico na USF, além da oferta de um trabalho com grupos de dependência química e de um cronograma de ações educativas. Em relação à equipe e coordenação, existe uma avaliação de que houve uma mudança, ainda que discreta, de um olhar fiscalizador para um olhar facilitador, que permitiu a concretização de parcerias e ampliou uma visão de 'fachada' para uma visão ampliada da situação.

O sexto e último caso selecionado para análise foi trazido por um residente e diz respeito a um grupo com pacientes diabéticos insulino-dependentes, com o objetivo de promover o autocuidado e utilizar corretamente o glicosímetro. O grupo que inicialmente teve um grande número de participantes era fechado e tinha boa adesão. Havia uma coordenadora, mas a cada encontro um profissional da saúde era convidado para discussão de um tema relacionado à doença. Ao que parece, havia bastante participação dos presentes, constituindo-se em palestras dialogadas, com ênfase em temas biomédicos.

Ao final do ano, embora o grupo já estivesse reduzido, a coordenação fez um levantamento para verificar novos temas de interesse e, para sua surpresa, os usuários solicitaram os mesmo temas abordados ao longo dos encontros anteriores. Este fato levanta a hipótese de que o desejo de conti- 
nuar, mesmo a partir dos mesmos temas, evidencia, de um lado, os ganhos e aquisições e, de outro, o reconhecimento dos limites da equipe na abordagem de outros aspectos subjacentes ao processo de adoecimento e tratamento. Os profissionais da saúde, em geral, não possuem formação para o manejo de grupos, o que se traduz na dificuldade de 'abrir' para o trabalho com a subjetividade, que é a própria essência do trabalho grupal.

Assim, o desejo dos participantes em dar continuidade aos encontros denota que o vínculo formado é uma oportunidade para a abertura do grupo a novos participantes e também para o aprofundamento do trabalho visando à mudança de hábitos, tão importante quando desafiadora no controle de patologias crônicas. A mensagem parecia ser: se é isso que vocês podem oferecer, vamos começar tudo de novo, com os mesmos temas. Mas vamos continuar juntos.

Também é importante observar que, num trabalho de grupo, sempre há os que desistem e os que persistem; os que evoluem mais rápido e os que vão evoluindo devagar. O grupo é um espaço privilegiado para o aprendizado do respeito às diferenças e ao conhecimento que se baseia na experiência vivida (e absorvida) e não apenas na aquisição de informações. Conhecimento que se transmuta em sabedoria ao ser colocado em prática.

\section{Conclusões e recomendações}

A maior parte dos integrantes do grupo gestor da Atenção Básica do município de Amparo já tinha uma história compartilhada, alguns com anos de convivência, durante duas gestões, que foram marcadas por um forte compromisso com a implantação da Estratégia de Saúde da Família e a reformulação do SUS municipal. Já vinham construindo uma grupalidade, através de um objetivo comum que os unia. No entanto, todo grupo tem conflitos e dificuldades para lidar com os diferentes perfis de personalidades e, dependendo do nível de conflito, é conveniente ter alguém de fora na coordenação do trabalho grupal, que não esteja contaminado pelo fluxo de afetos existente e ajude a construir um 'espaço protegido' para que as dificuldades e os conflitos possam aparecer e ser solucionados.

Um grupo, quando efetivamente constrói vínculos de confiança e afeto, pode acolher comportamentos destrutivos (insegurança, raiva, competição, inveja) e fazer preponderar os sentimentos construtivos de cooperação. Uma imagem que pode ajudar a perceber estes movimentos é a de um jogo de futebol, onde, apesar da competição interna ao time, os jogadores buscam jogar a melhor bola possível para o outro, procurando vencer no coletivo. Ao contrário, numa partida de tênis, a jogada visa a colocar a pior bola possível para derrotar o parceiro. Assim também podemos observar o cotidiano 
das inter-relações, que podem se assemelhar mais com um ou com outro destes esportes.

É importante perceber que as diferenças podem significar acréscimos, novos olhares, visões de mundo. Que, em conjunto, consegue-se construir soluções mais ricas. Que, quem está com a mão na massa, tem condições de encontrar melhores saídas, pois as teorias, por melhor que sejam, apresentam sempre um recorte da realidade e, no máximo, podem apoiar, dar suporte e potencializar a criatividade e a competência existente no grupo.

Entrar em contato e acolher as dificuldades, por mais paradoxal que pareça, fortalece o grupo. Primeiro porque se percebe que todo mundo tem fragilidades. O problema que uma unidade de saúde tem, a outra também o vive, em grau diferente, de forma distinta, ou até já conseguiu equacionar de alguma forma. Mas nada é perfeito. A vida não é perfeita; o curso também não; a ESF no município de Amparo tem problemas; no Brasil também. No mundo, a atenção primária e a atenção à saúde, em geral, têm muitos problemas! Nós vamos acabar os encontros e os casos vão continuar e os conflitos também. Vamos fazer o melhor que pudermos dentro do prazo que temos, mas o grupo continua e os problemas também.

Temos de estabelecer uma relação dialética conosco e perceber que a consciência de nossas fraquezas pode ser a nossa força. Identificamo-nos com a fraqueza do outro, não com a perfeição, pois esta nos inibe, assusta e afasta. A fraqueza, a fragilidade, ao contrário, nos aproxima. Existe um lado infantil em cada um de nós que acha que tem de ser amado incondicionalmente e que vamos ser amados incondicionalmente quando formos completos, perfeitos. Então, corremos tanto atrás da completude e da perfeição, que vivemos na infelicidade, na frustração e na angústia, que muitas vezes é paralisante. À medida que as limitações, fragilidades e imperfeições são reconhecidas e compartilhadas, o grupo vai se 'empoderando' e se perguntando: “O que posso fazer de melhor com o que eu sou, com a minha experiência, com o que eu tenho, com a minha equipe, com o que meu município pode proporcionar neste momento? Como eu posso fazer o melhor com o que está ao meu alcance? Sem estresse, sem adoecer, lidando com os meus limites e com os limites da atual política de saúde? Como aperfeiçoar as práticas e melhorar a Atenção Básica em saúde dentro dos limites estruturais que ainda estão presentes?"

Muitas 'tecnologias leves', 'relacionais', podem ser adquiridas com algum treino. Diminuem, por exemplo, a expectativa imensa de que os professores existem para dar receita, solução. Que, mesmo diante de professores brilhantes, a troca de experiência de um grupo é sempre muito rica e potencializa as ofertas teóricas. Não basta a informação! É necessário que ela esteja contextualizada na experiência e que possa florescer sem que sentimentos de angústia ou impotência obstruam sua colocação em prática. O manejo da 
grupalidade também estimula a criatividade, a confiança do próprio grupo na sua capacidade de enfrentar conflitos e dificuldades e buscar o conhecimento e a informação que auxilie.

Partilhar a angústia é uma coisa que alivia, 'limpa a chaminé'! Quando expressamos o que sentimos e não deixamos acumular, evitamos que em momentos de tensão e descontrole a raiva seja 'vomitada' em cima do outro, destruindo, em minutos, relações que levaram muito tempo para ser construídas. Assim, é importante a criação de um 'ambiente protegido, acolhedor', onde sentimentos difíceis possam ser expressos e acolhidos em qualquer grupo: na família, na equipe, na gestão.

É bom lembrar ainda que crescer, amadurecer é assumir responsabilidades. E isto geralmente é sofrido, dá trabalho e nem sempre é desejado. Empurrar as responsabilidades para os outros, sejam gestores, governos, profissionais ou usuários, pode ser mais fácil que assumir a nossa parte na responsabilidade coletiva. Amadurecer emocionalmente e assumir as próprias escolhas é um processo tão doloroso quanto necessário. Quando nos abrimos no grupo para o olhar do outro, os outros veem nossas sombras com mais clareza e as refletem como um espelho. Por isso muitos se recusam a fazer análises, pelo medo de contatar a própria sombra.

Conviver com o poder, compreendido em seu aspecto positivo de 'poder fazer', 'poder realizar', é muito ambíguo. O poder traz o bônus de realizar algo, mas traz também muitos ônus e muita responsabilidade. Quando tentamos democratizar o poder, torná-lo mais participativo ou mesmo implantar uma cogestão, muitas vezes verificamos que os outros não estão dispostos a pagar o preço de assumir parte desse poder e das responsabilidades. Surge muita 'cobrança' imatura de quem quer só o bônus, privilégios, sem a contrapartida, que é o ônus da responsabilização.

Um grupo integrado, preparado emocionalmente e amadurecido, certamente prestará melhor assistência à saúde da população, com menos absenteísmo e adoecimentos e maior realização profissional. 


\section{Notas}

1 Socióloga, Secretaria de Estado da Saúde/Diretoria Regional de Piracicaba, São Paulo, Brasil. Doutorado em Economia do Setor Público e pós-doutorado pela Universidade Estadual de Campinas (Unicamp), Campinas, Brasil. <anaf@fcm.unicamp.br> Correspondência: Rua Doutor Lauro Pimentel, 33, Campinas, São Paulo, Brasil, CEP 13083-250.

2 Professor-Assistente da Universidade Estadual de Campinas (Unicamp), Campinas, Brasil. Doutorado em Ciências Médicas pela Unicamp. <jfoj1950@gmail.com>

3 Teve como base empírica uma pesquisa de pós-doutoramento de Ana Maria Franklin de Oliveira, que contou com a colaboração do professor Gastão Wagner de Sousa Campos e do professor Jair Franklin Oliveira Júnior, além do apoio de Mariana Dorsa Figueiredo, psicóloga e doutoranda do Departamento de Medicina Preventiva e Social da Faculdade de Ciências Médicas, da Universidade Estadual de Campinas (DMPS/FCM/Unicamp).

\section{Referências}

AMPARO (município). Secretaria Municipal de Saúde. Relatório de gestão da Secretaria Municipal de Saúde de Amparo. Prefeitura Municipal, 2006, 2007. Mimeografado.

BALINT, Michael. O médico, seu paciente e a doença. Rio de Janeiro; São Paulo: Atheneu, 1988.

BION, Wilfred Ruprecht. Experiências com grupos. Rio de Janeiro: Imago, 1975.

BOÈTIE, Etienne de la. O discurso da servidão voluntária. São Paulo: Brasiliense, 1982.

CAMPOS, Gastão Wagner de Sousa. Um método para análise e co-gestão de coletivos. São Paulo: Hucitec, 2000.

CAPOZZOLO, Angela Aparecida. No olho do furacão: trabalho médico e o Programa de Saúde da Família. Dissertação (Mestrado em Saúde Coletiva). Departamento de Medicina Preventiva e Social, Faculdade de Ciências Médicas, Universidade Estadual de Campinas, Campinas, 2003.
CORTESÃO, Eduardo Luís. Grupanálise. Lisboa: Fundação Calouste Gulbenkian, 1989.

FOULKES, Siegmund R. Group psychotherapy: the psychoanalytic approach. Harmondsworth Middlex: Penguin, 1971.

LOURAU, René. A análise institucional. Petrópolis: Vozes, 1995.

MINAYO, Maria Cecília S. O desafio do conhecimento. São Paulo, Rio de Janeiro: Hucitec, Abrasco, 2000.

OLIVEIRA, Ana Maria Franklin et al. Espirais D'Ascese: as contribuições de Balint e da psicologia grupal para potencializar o Método da Roda. In: CAMPOS, Gastão Wagner de Sousa; GUERREIRO, André Vinícius Pires (Orgs.). Manual de práticas da Atenção Básica. São Paulo: Hucitec, 2008.

Espirais D'Ascese: estratégia de ampliação da clínica e manejo de grupos e outros coletivos. Relatório final de pesquisa. Biblioteca Virtual da Universidade Estadual de Campinas, Campinas, 2008b. Mimeografado. 
OLIVEIRA JUNIOR, Jair Franklin. Grupo de reflexão no Brasil. Taubaté: Cabral Livraria e Editora Universitária, 2003.

Niveis de experiência e interpretação em grupanálise: um estudo das ideias de Cortesão. Tese (Doutorado em Saúde Mental). Faculdade de Ciências Médicas, Universidade de Campinas, Campinas, 2000.

OSÓRIO, Luiz Carlos. Grupos, teorias e práticas. Porto Alegre: Artmed, 2003.
PICHON-RIVIÈRE, Enrique. O processo grupal. São Paulo: Martins Fontes, 1986.

THIOLLENT, Michel. Metodologia da pesquisa-ação. São Paulo: Cortez, 1988.

ZIMERMAN, David E. Fundamentos básicos das grupoterapias. Porto Alegre: Artmed, 2000.

Recebido em 04/05/2009

Aprovado em 09/07/2009 